\title{
Cancer Therapy and Research Center
}

National Cancer Institute

\section{Source}

National Cancer Institute. Cancer Therapy and Research Center. NCI Thesaurus. Code C39511.

The mission of the Cancer Therapy and Research Center is to conquer cancer through research, prevention and treatment. The Center accelerates the development of anticancer agents by integrating basic, translational, and clinical research on the University of Texas campus and attracts patients from the community and beyond to join Phase I, II, and III studies. It became an NCl-designated cancer center in 1993. 